\title{
Cardiology and COVID-19: A bidirectional association!
}

\section{To the Editor}

The novel corona virus pandemic has the world in its grip and infection with COVID-19 has proven to be beyond a pulmonary disease. There are pre-existing cardiac conditions predisposing to it and the cardiological manifestations of the disease are being increasingly recognised.

The previous viral pandemics and epidemics have shown that viral infections are more likely to occur in patients with underlying cardiovascular disease [1]. Viral myocarditis is a prominent infectious-inflammatory disease reported with the previous corona virus epidemics [2, 3]. Even longterm follow up of the survivors of the previous viral epidemics has documented cardiovascular and metabolic abnormalities [4].

The published medical literature on COVID-19 relevant to cardiology is summarised in Table 1. There is mounting evidence that underlying cardiovascular conditions lead to a higher likelihood of infection, more severe disease progression, and a greater risk for mortality from COVID-19. Also, studies evaluating patients with COVID-19 presenting with cardiac injury show that they have a poorer outcome. It is important for physicians to realise the importance of cardiac disease as a risk factor and potential complication of the disease because this might help in improving the management and treatment of infected patients.

Early measurement of cardiac biomarkers (troponin and NT-pro BNP) of a suspected infected patient can help identify cardiac injury. However, it is important to realise that biomarkers of cardiac injury often rise in hospitalized patients and that its interpretation and actionability would require careful consideration. Electrocardiography (ECG) is instrumental in assessing for arrhythmia, and echocardiography (ECHO) is a convenient bedside test to assess for cardiac systolic and diastolic function. The other test for assessing cardiac function is a cardiac MRI. CT and Doppler may assist in detecting the thrombotic complications in a patient.

It is still not clear whether the cardiac manifestations are because the cardiac myocytes are the primary target or secondary bystander. Minimally invasive autopsies from lung, heart, and other sites of COVID-19 patients have shown that, while the virus does have a predilection for the lungs, the infection also results in damage to the heart, vessels, liver, kidney, and other organs [5]. Cardiac manifestations are likely due to a multifactorial aetiology; the myocardial damage could be related to the direct effect of the virus or may occur indirectly with increased oxygen demands due to tachycardia and fever, and reduced oxygen delivery due to hypotension and hypoxemia. Another possibility is that the enhanced inflammatory state can induce vascular inflammation, myocarditis, and cardiac arrhythmias [6]. The resulting cytokine storm can elicit activation of cells within pre-existing atherosclerotic lesions thus augmenting thrombotic risk and risk of ischemic syndromes. Moreover, microvascular activation by cytokines can cause myocardial injury along with harm to other organ systems [7]. Besides these causes, the possible impacts of the drugs currently used to treat COVID-19 cannot be ignored. Some of the drugs that are frequently used to manage these cases are known to prolong the QT interval and can have a proarrhythmic propensity resulting in cardiac complications [8,9].

Address for correspondence: Siddharth Raj Yadav, Department of Pulmonary, Critical Care and Sleep Medicine, VMMC and Safdarjung Hospital, New Delhi, India;

e-mail: drsid28@gmail.com

DOI: 10.5603/ARM.a2020.0169

Received: 22.06.2020

Copyright (C) 2021 PTChP

ISSN 2451-4934 


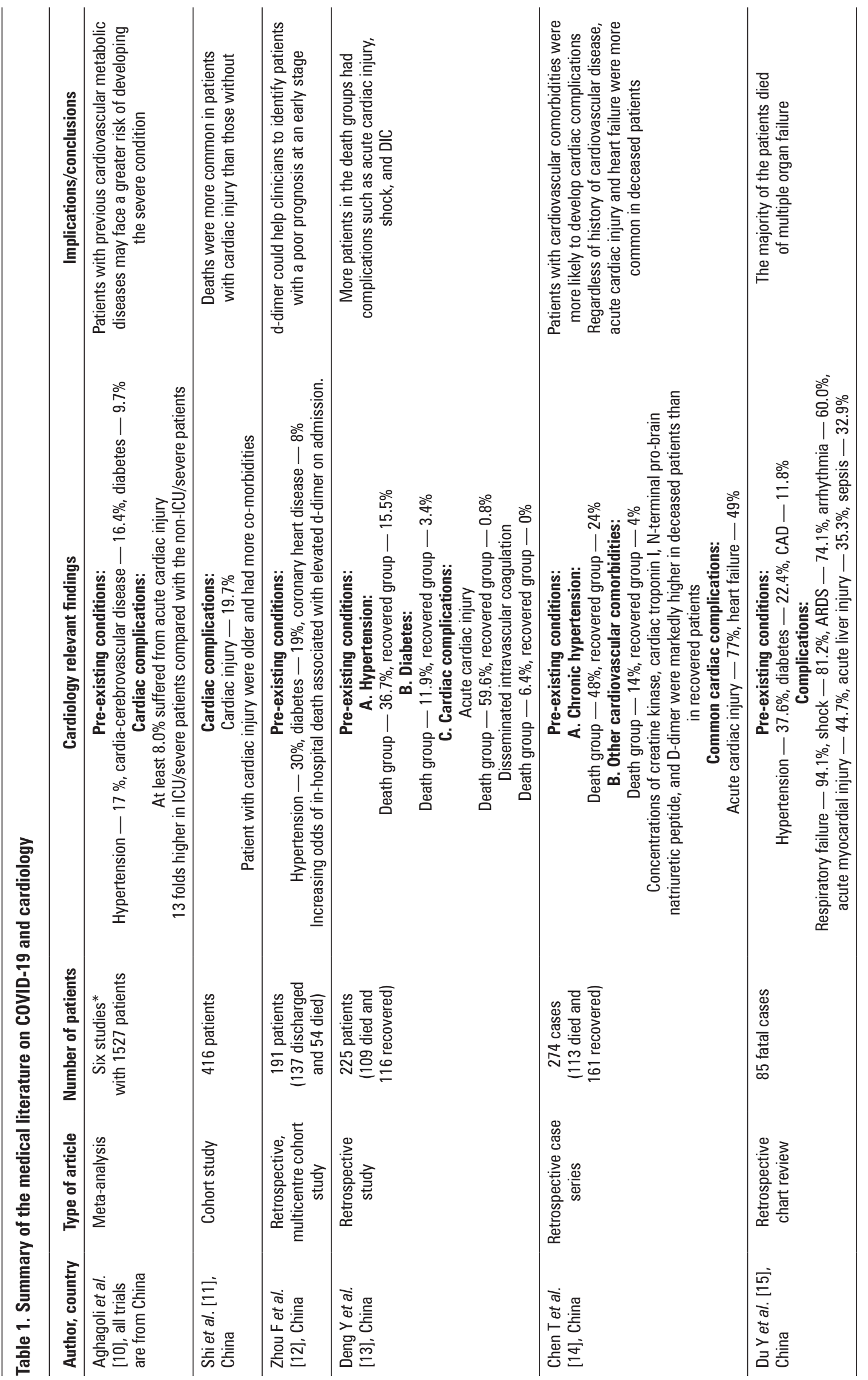




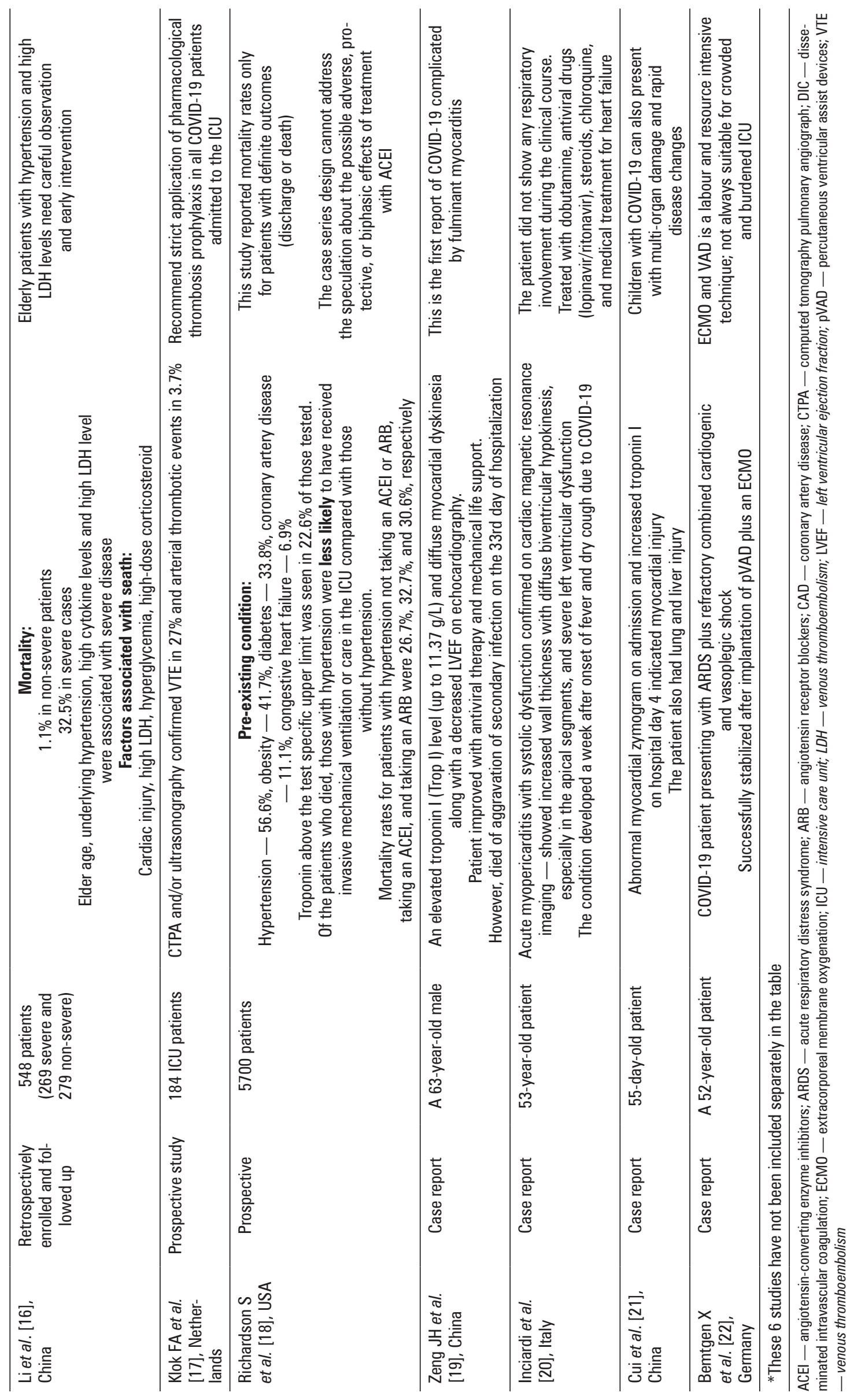


As the pandemic progresses, our knowledge on this novel infection will evolve. We have sufficient evidence of an increased severity of COVID-19 infection in patients with cardiac diseases and more mortality in patients with COVID-19 related cardiac failure and myocarditis. It is important to alert clinicians of this because it would aid in the timely diagnosis of the cardiac complications. It is also important to acknowledge our poor understanding of the exact pathogenesis because currently, the possible role of angiotensin receptors and the possible longterm effects of this virus are still to be assessed. Trials proving an optimal management strategy have not yet been completed, therefore, the best management that can currently be offered is of a supportive nature. Thus, constant physician vigilance of the clinical presentation of such patients can help in reducing morbidity and mortality until further evidence surfaces.

\section{Conflict of interest}

None declared.

\section{References:}

1. Badawi A, Ryoo SG. Prevalence of comorbidities in the Middle East respiratory syndrome coronavirus (MERS-CoV): a systematic review and meta-analysis. Int J Infect Dis. 2016; 49: 129-133, doi: 10.1016/j.ijid.2016.06.015, indexed in Pubmed: 27352628 .

2. Fung G, Luo H, Qiu Ye, et al. Myocarditis. Circ Res. 2016; 118(3): 496-514, doi: 10.1161/CIRCRESAHA.115.306573, indexed in Pubmed: 26846643.

3. Alhogbani T. Acute myocarditis associated with novel Middle East respiratory syndrome coronavirus. Ann Saudi Med. 2016; 36(1): 78-80, doi: 10.5144/0256-4947.2016.78, indexed in Pubmed: 26922692.

4. Wu Qi, Zhou L, Sun X, et al. Altered lipid metabolism in recovered SARS patients twelve years after infection. Sci Rep. 2017; 7(1): 9110, doi: 10.1038/s41598-017-09536-z, indexed in Pubmed: 28831119.

5. Yao XH, Li TY, He ZC, et al. A pathological report of three COVID-19 cases by minimal invasive autopsies. Zhonghua Bing Li Xue Za Zhi. 2020; 49(5): 411-417, doi: 10.3760/ cma.j.cn112151-20200312-00193, indexed in Pubmed: $\underline{32172546 .}$.

6. Madjid M, Safavi-Naeini P, Solomon SD, et al. Potential effects of coronaviruses on the cardiovascular system: a review. JAMA Cardiol. 2020; 5(7): 831-840, doi: 10.1001/jamacardio.2020.1286, indexed in Pubmed: 32219363.

7. Libby P. The heart in COVID-19: primary target or secondary bystander? JACC Basic Transl Sci. 2020; 5(5): 537-542, doi: 10.1016/i.jacbts.2020.04.001, indexed in Pubmed: 32292847.
8. Sakabe M, Yoshioka R, Fujiki A. Sick sinus syndrome induced by interferon and ribavirin therapy in a patient with chronic hepatitis C. J Cardiol Cases. 2013; 8(6): 173-175, doi: 10.1016/i. jccase.2013.08.002, indexed in Pubmed: 30534284.

9. Kochi AN, Tagliari AP, Forleo GB, et al. Cardiac and arrhythmic complications in patients with COVID-19. J Cardiovasc Electrophysiol. 2020; 31(5): 1003-1008, doi: 10.1111/jce.14479, indexed in Pubmed: 32270559.

10. Aghagoli G, Gallo Marin B, Soliman LB, et al. Cardiac involvement in COVID-19 patients: Risk factors, predictors, and complications: A review. J Card Surg. 2020; 35(6): 1302-1305, doi: 10.1111/jocs.14538, indexed in Pubmed: 32306491.

11. Shi S, Qin $\mathrm{Mu}$, Shen Bo, et al. Association of cardiac injury with mortality in hospitalized patients with COVID-19 in Wuhan, China. JAMA Cardiol. 2020; 5(7): 802-810, doi: 10.1001/ jamacardio.2020.0950, indexed in Pubmed: 32211816.

12. Zhou F, Yu T, Du R, et al. Clinical course and risk factors for mortality of adult inpatients with COVID-19 in Wuhan, China: a retrospective cohort study. Lancet. 2020; 395(10229): 1054-1062, doi: 10.1016/S0140-6736(20)30566-3, indexed in Pubmed: $\underline{32171076}$.

13. Deng Y, Liu W, Liu K, et al. Clinical characteristics of fatal and recovered cases of coronavirus disease 2019 in Wuhan, China: a retrospective study. Chin Med J (Engl). 2020; 133(11): 1261-1267, doi: 10.1097/CM9.0000000000000824, indexed in Pubmed: 32209890 .

14. Chen T, Wu D, Chen H, et al. Clinical characteristics of 113 deceased patients with coronavirus disease 2019: retrospective study. BMJ. 2020; 368: m1295, doi: 10.1136/bmj.m1295, indexed in Pubmed: 32234718.

15. Du Y, Tu L, Zhu P, et al. Clinical features of 85 fatal cases of COVID-19 from Wuhan. A retrospective observational study. Am J Respir Crit Care Med. 2020; 201(11): 1372-1379, doi: 10.1164/rccm.202003-0543OC, indexed in Pubmed: 32242738.

16. Li X, Xu S, Yu M, et al. Risk factors for severity and mortality in adult COVID-19 inpatients in Wuhan. J Allergy Clin Immunol. 2020; 146(1): 110-118, doi: 10.1016/.jaci.2020.04.006, indexed in Pubmed: 32294485.

17. Klok FA, Kruip MJ, van der Meer NJM, et al. Incidence of thrombotic complications in critically ill ICU patients with COVID-19. Thromb Res. 2020; 191: 145-147, doi: 10.1016/j. thromres.2020.04.013, indexed in Pubmed: 32291094.

18. Richardson S, Hirsch JS, Narasimhan M, et al. Presenting characteristics, comorbidities, and outcomes among 5700 patients hospitalized with COVID-19 in the new york city area. JAMA. 2020; 323(20): 2052-2059, doi: 10.1001/iama.2020.6775, indexed in Pubmed: $\underline{32320003 .}$.

19. Zeng JH, Liu YX, Yuan J, et al. First case of COVID-19 complicated with fulminant myocarditis: a case report and insights. Infection. 2020; 48(5): 773-777, doi: 10.1007/s15010-02001424-5, indexed in Pubmed: $\underline{32277408 .}$

20. Inciardi RM, Lupi L, Zaccone $\mathrm{G}$, et al. Cardiac involvement in a patient with coronavirus disease 2019 (COVID-19). JAMA Cardiol. 2020; 5(7): 819-824, doi: 10.1001/jamacardio.2020.1096, indexed in Pubmed: 32219357.

21. Cui Y, Tian M, Huang D, et al. A 55-day-old female infant infected with 2019 novel coronavirus disease: presenting with pneumonia, liver injury, and heart damage. J Infect Dis. 2020; 221(11): 1775-1781, doi: 10.1093/infdis/iiaa113, indexed in Pubmed: 32179908.

22. Bemtgen X, Kruger K, Supady A, et al. First successful treatment of COVID-19 induced refractory cardiogenic plus vasoplegic shock by combination of pVAD and ECMO - a case report. ASAIO J. 2020; 16. 